\begin{tabular}{|c|c|}
\hline 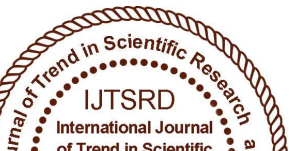 & $\begin{array}{l}\text { International Journal of Trend in Scientific } \\
\text { Research and Development (IJTSRD) }\end{array}$ \\
\hline 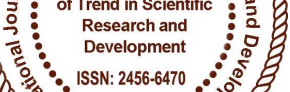 & International Open Access Journal \\
\hline 000 & ISSN No: 2456 - 6470 | www.ijtsrd.com | Volume - 2 | Issue - 3 \\
\hline
\end{tabular}

\title{
Smart Prevention System to Protect Women Incensorious Situation
}

\section{Vidhya. S}

Department of Computer Science and Engineering, Prince Shri Venkateshwara Padmavathy Engineering College, Chennai, India

\section{Shema. $\mathbf{N}$}

Department of Computer Science and Engineering, Prince Shri Venkateshwara Padmavathy Engineering College, Chennai, India

\author{
Reena. $\mathbf{R}$ \\ Assistant Professor, Department of Computer Science \\ and Engineering, Prince Shri Venkateshwara \\ Padmavathy Engineering College, Chennai, India
}

Kapila Vani. R. K

Assistant Professor, Department of Computer Science and Engineering, Prince DR.K Vasudevan college of

Engineering and Technology, Chennai, India

\section{ABSTRACT}

In today's world, people using smart phones have increased rapidly and hence, a smart phone can be used efficiently for personal security or various other protection purposes. Children and women are facing many security related problems. In such situations, they are helpless and don't have any way to protect them or inform it to their family members, neighbours or police station and they feel as handicaps. Hence there should be a system to protect them in such times. This paper presents Shake Alert, an Android Application for the Safety of Women and this app can be activated by a shake, whenever need arises. For that, the system contains GPS to detect location and GSM mechanisms to pass their current location to their trusted contacts as a google map link and services are provided to track the locations to save the person. The unique feature of this application is to send the message to the registered contacts and they can also view the nearby police station with their contact information.

Keywords: Smart Phones, Shake Alert, Android Application, Shake, GPS, GSM, Track

\section{INTODUCTION}

The misbehaviours against children and women are increasing day by day. They are under the threat of easily being kidnapped. In such unsafe situations there must be a mechanism that is easily affordable to handle those situations. Hence this system combines both GPS and GSM technology to provide a hand in

such situations. The GPS is used for identifying the locations and GSM is used for sending them as a message.

Global Positioning System (GPS): GPS receiver is a navigation system. It works based on satellite signals. It pinpoints the geographical location of itself. The GPS satellite rotates around the earth and transmits signals to the earth.

Global System for Mobile Communication (GSM): GSM stands for Global System for Mobile communication. It was originally developed with the help of digital technology which can carry data up to the rate of $64 \mathrm{kbps}$ to $120 \mathrm{mbps}$. It uses the variations of Time Division Multiple Access (TDMA) technique for transmission of signals. GSM provides many services; some basic services are voice and data services including roaming services. The working of GSM starts with digitization and compression of user data then sending the user data stream through a channel. It's frequency band limit is either $900 \mathrm{MHz}$ or $1800 \mathrm{MHz}$. In our system, one of the services of GSM is Short Message Service (SMS) which is used to share the location information from the system to helper's mobile

\section{OBJECTIVE AND SCOPE}

Explore and contextualise local women's experiences and perspectives within their particular context. Describe and analyze women's accounts of their 
involvement \& roles in violence prevention, safety promotion and peace building activities. Examine the meanings women attribute. Voice and visibility to local women's leadership and agency. Case example: volunteer group involved in safety promotion/violence prevention programme. Contribution to development of gendered, contextualised and culturally sensitive approach. The scope of our project is, Security is the most important factor for safety of women. In this paper we have discussed in details, how easily the women can be protected from harassments and rapes which are increasing day-by-day. As this system is wired system, in future it can be made wireless using Bluetooth.

\section{EXISTING SYSTEM}

The women have to dial a number to call a police or send a Short Messaging Service (SMS) to the particular subscriber code, after they received the service they will get in touch with you later and there is no time to make a call or SMS. There are also so many volunteer organizations all over the world to help them, but they could not able to get those messages. The existing application is the lack of situational awareness and communication terminology among their respective. Due to this response and recovery is Difficult to the authorities. There are several different disadvantages in this system such that the user cannot transmit the data of their location immediately and cannot protect the devices as soon as possible. May give less accurate location as it takes one shot location wherever needed. A human interface is needed every time and Maintaining is too tough.

\section{PROPOSED SYSTEM}

We use an Android based smart phone with an integrated tri-axial accelerometer. Data from the accelerometer is evaluated with several threshold based algorithms and position data to determine. The threshold is adaptive based on user provided parameters such as: height, weight, and level of activity. The algorithm adapts to unique movements that a phone experiences as opposed to similar systems which require users to mount accelerometers to their chest or trunk. It is very powerful software especially developed for the safety of girls, whenever somebody is in trouble they don't have to sit and find contacts or find ways to send short message service.

Our system provides a realizable, cost effective solution to detection using a simple graphical interface while not overwhelming the user with uncomfortable sensors.

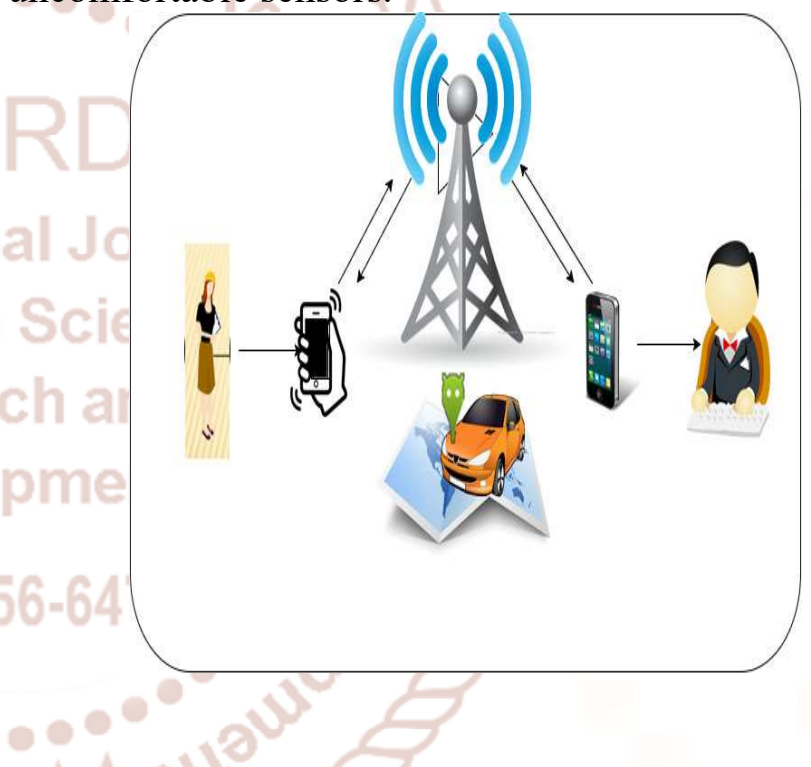

\section{SYSTEM ARCHITECTRE}

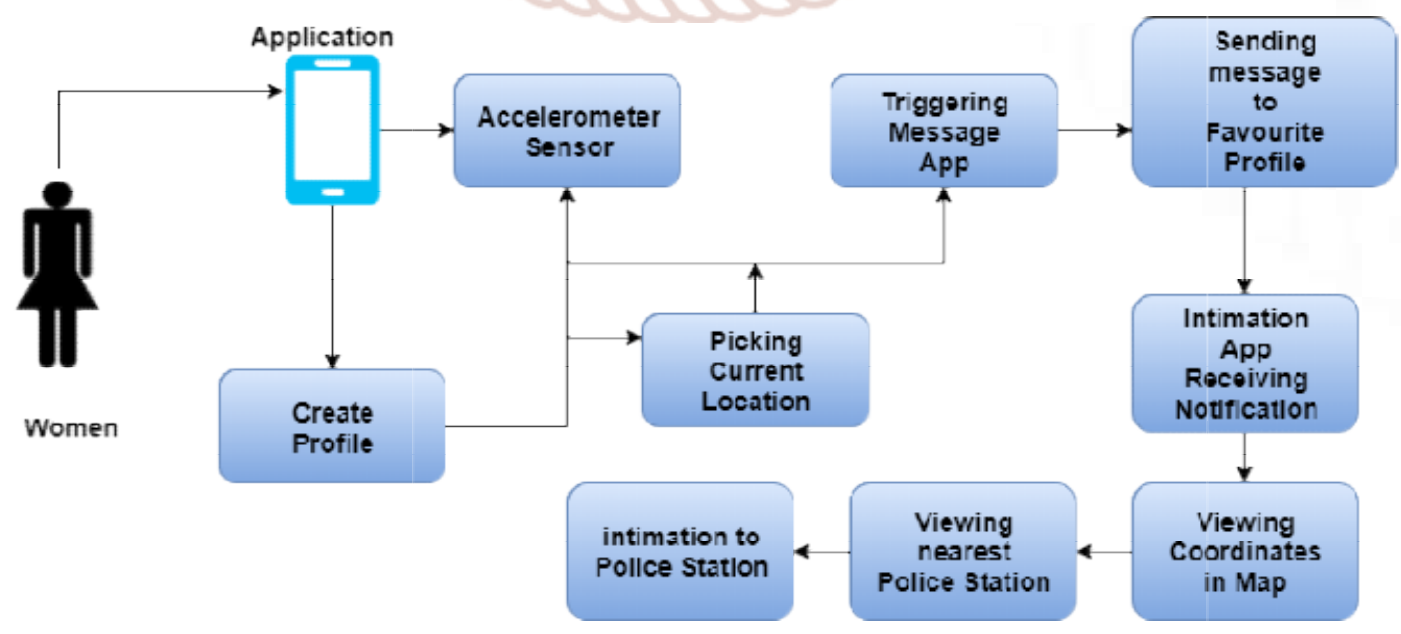


This system can be implemented in three ways as follows:

a. Monitoring and Alerting about SMS: The Parent can monitor their Child cell phone by receiving SMS alerts from the Child android based mobile device. In this it additionally sends the information about the persons who is in danger and the alert will send to the concerned persons. Here the Parents or concerned person can have details about the alert in order to take necessary steps to avoid the child unnecessary activities.

\section{b. Monitoring and Alerting about current location} of the Women (Through GPS) :They are specially designed to track the current location of Women through GPS. So that the Parent can also monitor the Child where ever they are and also the current position they are available. Here it gives timely update to their Women current location as an SMS alert to their Parent mobile.

c. Maintaining the details in the centralized server: They are specially designed to give timely update to their Women current location as an SMS alert to their Parent mobile. All these details will be maintained in the centralized server.

\section{Algorithm used:}

\section{Fixed Interval :}

We first unify the family of existing algorithms by deriving them in a common Bayesian framework; as we shall see, all these algorithms stem from forward and/or backward Markovian properties of the state process, involve one (or two) out of four canonical probability density functions and can be derived from the systematic use of some generic properties of Gaussian variables which we develop in a specific toolbox.

On the other hand the methodology we use enables us to complete the set of existing algorithms by five new Kalman like smoothing algorithms, which is our second result.

\section{Radius :}

The Radius algorithm handles speed changes in the mobile asset, wherein any change in speed will result in change in frequency of the data sent to the database server.Their performance considerably improves when the step-size for LMS (or forgetting factor for RLS) is chosen according to the Doppler speed, that is the speed of a vehicle in which the receiver is located relative to the base station. A higher Doppler speed usually requires a higher step-size. However, it is not straight- forward to derive Doppler speed estimates from the received data.

\section{CONCLUSION AND FUTURE WORK}

The problem of the women safety is increased rapidly in this environment, so I proposed as an effective Android application to prevent such type of the suspicious or natural disaster, by alerting the concern authorities using the android mobile phone which helps to stop such type of illegal activates and to trace the concern. In this, a low cost women tracking system using GPS and GPRS of GSM network, suitable for wide range of applications all over the world. The combination of the GPS and GPRS provides continuous and real time tracking. The cost is much lower compared to SMS based tracking systems. Free Google map and the use of HTTP protocol as data sending method reduces the monthly bundle cost for the individual user and also for the small business owner. It is expected that the full implementation of the proposed system would ultimately replace the traditional and costly SMS based tracking systems. This mobile application is helpful in future when any problem arises in travelling or any kind of situations. As the technology emerges, it is possible to upgrade the system and can be adaptable to desired environment. Because it is based on object-oriented design, any further changes can be easily adaptable. Based on the future security issues, security can be improved using emerging technologies.

\section{REFERENCES}

1. ROGER S. Pressman "Software Engineering: A Practitioner's Approach", SEVENTH EDITION McGraw-Hill International edition 2010, Page No.1-888

2. "WOMEN'S SECURITY", Android AppdevelopedbyAppSoftIndia,December17,2013

https://play.google.com/store/apps/details?id=com .zayaninfotech

3. http://en.wikipedia.org/wiki/andorid

4. http://timesofindia.indiatimes.com/topic/mobileapps-for-women's-safety

5. Laird Dornin "Programming Andr id" second edition "O'Reilly Media, Inc.", 2012 -1-542 pages.

6. Bramarambika Thota, Udaya Kanchana Kumar .P, Sauver: An Android Application For Women Safe-ty, MTech , Dept.Of ECE ,Vignan University, Guntur , India , M.sc , Computer 
Science , TJPS Co-lege,Guntur,India ,IJTEEE ,ISSN:2347-4289.VOL 3,ISSUE 05.

7. S.Sangeetha1,P.Radhika PG scholar, Application For Women Safety,Department Of MCA, Panimalar Engineering College,IOSR,ISSN:22780661,p-ISSN:2278-8727, Volume 17,ISSUE 3

\section{BIOGRAPHY}

Vidhya.S is a student doing B.E degree in computer science and engineering in Prince shri venkateshwarapadmavathy Engineering college, Chennai. Her research interest includes network security, theory of computation.

Shema. $\mathbf{N}$ is a student doing B.E degree in computer science and engineering in Princeshrivenkateshwarapadmavathy Engineering college, Chennai. Her research interest includes visual cryptography, information security.

Reena.R as an assistant professor in computer science department at Prince ShriVenkateshwarapadmavathy Engineering college, Chennai. She is a M.E graduate. Her research interest includes computer graphics, internet programming, mobile computing.

Kapila Vani.R.K as Assistant Professor in computer science department at Prince Dr. K. Vasudevan College of Engineering and Technology, Chennai. She is a M.E graduate. Her research interest includes compiler design, Theory of computation and Software project management 